\title{
Selective laser trabeculoplasty: current perspectives
}

\author{
This article was published in the following Dove Press journal: \\ Clinical Ophthalmology \\ II May 2015 \\ Number of times this article has been viewed
}

\author{
Kate E Leahy' \\ Andrew JR White ${ }^{1-3}$ \\ 'Westmead Hospital, Westmead, \\ NSW, Australia; ${ }^{2}$ Centre for Vision \\ Research, Westmead Millennium \\ Institute, University of Sydney, Sydney, \\ NSW, Australia; ${ }^{3}$ Save Sight Institute, \\ University of Sydney, Sydney, NSW, \\ Australia
}

\begin{abstract}
Selective laser trabeculoplasty (SLT) has been used in the treatment of glaucoma for just over a decade. Here, we review the current literature in terms of suggested mechanism, efficacy, method of treatment, predictors of success, adverse events, repeatability, and cost of SLT. The exact mechanism by which SLT lowers intraocular pressure (IOP) remains unknown although circumstantial evidence has come in many forms in relation to structural alteration; oxidative stress and inflammatory responses; tight junction integrity; proliferative responses; and microbubble formation. SLT is as effective as argon laser trabeculoplasty and medications in reducing IOP in glaucoma and ocular hypertension. The treatment is not uniformly effective in all eyes, and its IOP-lowering effect decreases over time. High pretreatment IOP is the strongest predictor of success; however, significant pressure reduction has also been shown in normal-tension glaucoma and in patients already taking multiple antiglaucoma drops. Mild, transient adverse effects are common. Transient IOP spikes usually resolve quickly with or without antiglaucoma treatment but may be problematic in pigmented angles. The limited available evidence suggests SLT is repeatable and cost-effective for the treatment of glaucoma and ocular hypertension.
\end{abstract}

Keywords: glaucoma, SLT, ocular hypertension, intraocular pressure

\section{Key principles}

Selective laser trabeculoplasty (SLT) was designed to selectively target pigmented trabecular meshwork (TM) cells while sparing adjacent cells and tissues from thermal damage and maintaining TM architecture. In vitro investigation showed that nonpigmented cells did not experience collateral thermal or structural damage when a culture of mixed pigmented and nonpigmented TM cells were irradiated with frequencydoubled Nd:YAG laser at pulse durations less than $1 \mu \mathrm{s} .{ }^{1}$ The SLT parameters used clinically (532 $\mathrm{nm}$ frequency doubled Q-switched $\mathrm{Nd}$ :YAG laser with a 3 ns pulse and $400 \mu \mathrm{m}$ beam diameter) were based on the principle of selective photothermolysis, which relies on selective absorption of laser energy by pigmented TM cells and a pulse duration sufficiently short to prevent heat transfer and collateral tissue damage. This is because the nanosecond pulse duration is shorter than the time for the heat generated by the chromophore (melanin) to flow into the surroundings, which is in the range of microseconds. ${ }^{2}$ The selective targeting of pigmented TM cells, and the safety and morphologic effects of SLT in vivo were confirmed in owl monkeys. ${ }^{3}$

SLT was preceded by argon laser trabeculoplasty (ALT), a widely accepted treatment for open-angle glaucoma (OAG) providing successful intraocular pressure (IOP) control in $44 \%$ of eyes at 2 years, ${ }^{4}$ as well as experimental laser therapies to the TM dating back over 40 years. In 1974, Q-switched ruby laser goniopuncture of the anterior chamber angle was used to reduce IOP in 50 of 52 eyes by an average of $8.3 \mathrm{mmHg}$, with the effect lasting for a period of 3 months. ${ }^{5}$ 
The similar efficacy of both SLT and $\mathrm{ALT}^{6}$ has led to speculation that they produce their IOP-lowering effect through similar mechanisms, hence the coagulative damage to the TM with ALT may be unnecessary. ${ }^{7}$

\section{Suggested mechanisms Structural alteration}

The exact mechanism by which SLT lowers IOP remains incompletely understood. Circumstantial evidence has come in many forms. ${ }^{8,9}$ Histological studies have shown coagulative and mechanical damage occur minimally or not at all after SLT. Examination of human eye bank eyes with light microscopy, scanning, and transmission electron microscopy showed ALT caused crater formation, destruction of the ropelike components of the TM, and whitening of the surrounding collagen indicative of coagulative damage. The TM treated with SLT remained intact except for crack-like defects on the corneoscleral meshwork sheets; some of the endothelial cells contained disrupted intracytoplasmic pigment granules and some were vacuolated. ${ }^{8}$

Similarly, morphologic examination by light and transmission electron microscopy comparing ALT and SLT in patients 1-5 days prior to enucleation showed the extent of damage to the TM to be smaller after SLT. Post-ALT, trabeculae were markedly fragmented and the inner wall of Schlemm's canal was disrupted. Minor damage to trabeculae was seen after SLT; however, Schlemm's canal was well preserved and endothelial cells appeared less damaged with better-preserved nuclei than after ALT. ${ }^{9}$

Absent or minimal structural damage to the TM structure favors theories that SLT lowers IOP on a cellular level without mechanical or thermal effects. ${ }^{7,8}$ This could occur either through migration and phagocytosis of TM debris by macrophages, or by stimulating the growth of healthy TM to optimize the outflow pathway architecture. ${ }^{10,11}$

\section{Oxidative stress and inflammatory responses}

A rabbit model showed that a transient increase in aqueous lipid peroxide occurred between 3 hours and 7 days after SLT, which had predominantly normalized within 24 hours. This finding suggested that SLT may lead to liberation of free oxygen radicals, which then induce peroxidation of lipids or fatty acids. Potential sites of lipid peroxidation include the corneal endothelium and iris, which are rich in polyunsaturated fatty acids. Reactive oxygen metabolites also appear to participate in amplifying an inflammatory cascade and have direct cytotoxic effects. ${ }^{12}$

\section{Tight junction integrity}

An in vitro study showed the disassembly of ZO-1 tight junctions in cultured Schlemm's canal cells that were exposed to media conditioned by lasered TM cells, ${ }^{13}$ suggesting a role for intercellular junction changes in mediating the IOP-lowering effect of SLT by altering transendothelial aqueous flow across Schlemm's canal cells. Changes in ZO-1 tight junction staining were also seen in the corneal endothelium after SLT in cadaveric human donor corneas. ${ }^{14}$

\section{Proliferative responses}

Immunofluorescent staining of human cadaveric anterior segments exposed to media conditioned by ALT showed that intracellular IL-1 $\alpha$, IL-1 $\beta$, and TNF $\alpha$ increased in conditioned trabecular cells. Western immunoblot analysis of the culture media showed augmented levels of the matrix metalloproteinase stromelysin and cytokines IL- $1 \beta$ and TNF $\alpha$. This provided support to the theory that the therapeutic effect of laser trabeculoplasty is mediated by cytokine release, and proposed IL-1 $\beta$ and TNF $\alpha$ as the responsible factors. Blocking these two cytokines blocked the post-laser trabeculoplasty rise in stromelysin, a matrix metalloproteinase which may increase outflow facility by remodeling the juxtacanalicular extracellular matrix. ${ }^{15}$

A fivefold increase in monocyte population at the TM in eyes treated with SLT prior to enucleation and, in a separate experiment, a twofold increase in Schlemm's canal endothelial conductivity in cell cultures exposed to mononuclear cells from peripheral blood has been shown. ${ }^{16}$ Chemokines released during SLT may trigger monocyte recruitment to the TM which in turn then release cytokines, such as TNF $\alpha$, that could in turn modulate TM cells or alter the permeability of Schlemm's canal.

Laser trabeculoplasty to human corneoscleral explants in organ culture increased trabecular DNA replication by $80 \%$ during the first 2 days after ALT. ${ }^{17}$ A second study showed a fourfold increase in cell division, ${ }^{18}$ localized to the anterior nonfiltering TM, and migration of $60 \%$ of the new cells to the laser burn sites over the following 2 weeks. These findings support a hypothesis that laser trabeculoplasty causes early cell division by a population of cells from the anterior TM; these new cells then migrate and repopulate the treatment sites over the next few weeks.

The evidence supporting a cellular theory for the mechanism of SLT action correlates with the clinically observed time frame of IOP reduction occurring days to weeks after SLT. 


\section{Microbubble formation}

Clinically, the energy level used for SLT is usually titrated according to the appearance of microbubbles. ${ }^{3}$ Selective photodamage of the retinal pigment epithelium (RPE) is a new technique to treat a variety of retinal diseases without causing adverse effects to surrounding tissues such as the neural retina and choroid. There is histological evidence for RPE cell death occurring at the energy threshold for microbubble formation after this treatment. The most probable mechanism of cell damage is thought to be formation of transient microbubbles arising more or less simultaneously around melanosomes once the boiling point of the intracellular plasma is reached. Subsequently, the cell volume significantly increases transiently which leads to mechanically disrupted cell structures. Two weeks after laser exposure, lesions are covered by a new population of RPE cells. Four weeks after treatment, a morphologically restored RPE was found. ${ }^{19}$

\section{Efficacy}

The SLT pilot study ${ }^{20}$ was a nonrandomized prospective trial that followed 53 eyes of 53 patients with uncontrolled OAG, including 23 eyes previously treated with ALT. Seventy percent of eyes achieved an IOP reduction of at least 3 $\mathrm{mmHg}$ and at 26 weeks; the treatment response group showed a mean IOP reduction of $23.8 \%(5.9 \mathrm{mmHg})$.

SLT provides a clinically significant IOP reduction in patients with OAG. A recent meta-analysis ${ }^{21}$ identified 35 studies including eight randomized control trials (RCTs) assessing IOP reduction at 12 months or more post-SLT. Among patients with primary OAG (POAG), pseudoexfoliation (PXF), pigmentary, uveitic, steroid-induced, and normaltension glaucoma (NTG) as well as ocular hypertension (OHT), ranging from treatment-naive to those on maximum tolerated medical therapy, SLT resulted in a $6.9 \%-35.9 \%$ reduction in IOP.

The average reduction in IOP following SLT is $21.8 \%-29.4 \%$ at 6 months, ${ }^{22-25} 16.9 \%-30.0 \%$ at 12 months, ${ }^{6,24,26-30} 7.7 \%-27.8 \%$ at 2 years, ${ }^{24,28,31} 24.5 \%-25.1 \%$ at 3 years, ${ }^{24,28} 23.1 \%-29.3 \%$ at 4 years, ${ }^{24,28} 22.6 \%-32.1 \%$ at 5 years, ${ }^{24,32}$ and $22.8 \%$ at 6 years. ${ }^{24}$

The IOP-lowering effect of SLT decreases over time. SLT is effective in reducing IOP $\geq 20 \%$ below baseline pressure in $66.7 \%-75 \%$ eyes at 6 months, ${ }^{25,33,34} 58 \%-94 \%$ at 12 months, ${ }^{24,28,29,35,36} 40 \%-85 \%$ at 2 years, ${ }^{24,28,31} 38 \%-74 \%$ at 3 years, ${ }^{24,28,36,37} 38 \%-68 \%$ at 4 years, ${ }^{24,28,37}$ and $11.1 \%-31 \%$ at 5 years. ${ }^{23,36,37}$ The mean survival time (time for $50 \%$ of eyes to fail) is around 2 years. ${ }^{28,37}$ An IOP reduction $\geq 30 \%$ is seen in $48 \%-59 \%$ eyes at 12 months. ${ }^{29,35}$

\section{SLT versus medical treatment}

Four RCTs have compared SLT to medication. Meta-analysis of these studies showed that there was no statistically significant difference in IOP reduction $(0.85 \mathrm{mmHg}, 95 \%$ confidence interval $[\mathrm{CI}]-0.2$ to 1.9$)$ or treatment success (odds ratio [OR] 0.8, 95\% CI 0.33-2.0). ${ }^{21}$

SLT has the advantage of not relying on adherence with glaucoma medications, which has been found to be low in several studies. Electronic eye drop monitoring revealed $76 \%-86 \%$ drop compliance, and evaluation of prescription claims showed patients had glaucoma drops available to use $69 \%$ of the time. Persistence (time until the patient first discontinues their medication) was observed to range from $20 \%$ to $64 \%{ }^{38}$

\section{SLT versus ALT}

Ten RCTs comparing SLT to ALT showed that there was no significant difference in IOP reduction between the two types of laser trabeculoplasty. ${ }^{39}$ One RCT reported better outcomes with SLT after 1 year, but no difference after 2 years. ${ }^{31}$ Meta-analysis of four studies showed there was no statistically significant difference in absolute IOP reduction $(-0.5 \mathrm{mmHg}, 95 \% \mathrm{CI}-1.5$ to 0.4$)$, number of antiglaucoma drops ( -0.2 medications, $95 \% \mathrm{CI}-0.08$ to 0.5$)$, or treatment success (OR 1.2, 95\% CI $0.7-1.8) .{ }^{21}$

\section{SLT after prior ALT}

SLT can produce a clinically useful decrease in IOP, similar to that of SLT as a first laser procedure, in patients who have had prior ALT. A prospective, non-RCT found no significant difference in the IOP reduction at 1 year in patients receiving SLT as a first laser procedure or SLT after prior ALT. Mean IOP reductions were 23\% (SLT) and 19.3\% (SLT after ALT). ${ }^{26}$

\section{SLT as initial treatment}

SLT is effective as a first-line therapy to lower IOP and eliminates the issue of adherence to mediations when used as an initial treatment. ${ }^{40}$ The limited research on SLT as primary treatment in newly diagnosed POAG, PXF, and OHT suggests that the majority of patients maintain the IOP-lowering effect of SLT for up to 30 months $^{41}$ and even 5 years. ${ }^{32}$

\section{Concurrent medications}

A retrospective review of 206 patients found that the number of coexisting antiglaucoma medications did not shorten the duration of the clinically significant pressure reduction after SLT. At 5 years, the cumulative proportion of patients not 
requiring further intervention (such as additional medications, repeat SLT, or trabeculectomy) was $60.2 \%, 39.8 \%$, $57.4 \%$, and $45.7 \%$ of patients taking none, one, two, or three or more glaucoma medications, respectively. ${ }^{23}$ This correlates with an earlier retrospective review which found that specific classes of antiglaucoma medications were not associated with SLT success. ${ }^{33}$ These findings confirm a role for SLT as an adjunct to antiglaucoma medications, including prostaglandin analogs, which had been suggested may impair the effectiveness of SLT by competing for a common pathway to lower pressure. ${ }^{13}$

A prospective, nonrandomized study showed that SLT reduced the number of medications required to control IOP by an average of 2.0 (95\% CI 1.8-2.3) at 6 months and 1.5 (95\% CI 1.27-1.73) at 12 months. Ninety-seven percent of eyes attained a reduction in medications. ${ }^{42}$

\section{Reduction of diurnal IOP fluctuation}

SLT is effective in reducing diurnal IOP fluctuation ${ }^{34,43}$ although it may not be as effective as prostaglandin analogs in this respect. A prospective study showed mean diurnal IOP fluctuation was $5.5 \mathrm{mmHg}$ before treatment and this reduced by $2.5 \mathrm{mmHg} 4-6$ months after SLT and by $3.6 \mathrm{mmHg}$ in the latanoprost group. Fifty percent of patients in the SLT group achieved at least a $50 \%$ reduction in IOP fluctuation. ${ }^{34}$ A retrospective study found $100 \%$ of eyes with $360^{\circ}$ SLT and $84 \%$ eyes with $180^{\circ}$ treatment maintained an IOP fluctuation $<3 \mathrm{mmHg}$ during the period 6-24 months after SLT. A statistically significant difference was found between the $180^{\circ}$ and $360^{\circ}$ treatment regimes in the number of eyes achieving an IOP fluctuation $\leq 2 \mathrm{mmHg}\left(86 \%\right.$ after $360^{\circ} \mathrm{SLT}$ compared to $52 \%$ of eyes after $180^{\circ}$ SLT). ${ }^{43}$ A recent study measuring IOP fluctuations in patients with NTG using a contact lens sensor found a statistically significant decrease in the range of nocturnal IOP fluctuation 1-2 months after SLT. ${ }^{44}$

\section{NTG}

Although the strongest predictor determining SLT success is a higher pretreatment IOP, a significant IOP reduction can still be achieved in patients with NTG. IOP was shown to decrease from $13.5 \pm 2.5 \mathrm{mmHg}$ to $11.3 \pm 2.7 \mathrm{mmHg}(P=0.018)$ 3 months after SLT, ${ }^{44}$ although there is a paucity of data in this area.

\section{PXF glaucoma}

SLT in eyes with PXF has a similar efficacy and adverse event profile to other types of OAG. ${ }^{41,45-48}$ Studies have reported a mean IOP reduction for eyes with PXF in the range of $31.5 \%$ at 12 months, ${ }^{46} 16.6 \%$ at 16 months, ${ }^{47}$ and $31.4 \%$ at 18 months, ${ }^{45}$ with a cumulative probability of maintaining $\geq 20 \%$ IOP reduction in $64 \%$ of patients at 18 months $^{45}$ and $47 \%$ at 36 months, ${ }^{49}$ and successfully remaining off medical therapy without further SLT in 74\% at 30 months. ${ }^{41}$ Where comparisons were made to POAG or other glaucoma subtypes, no statistically significant difference in IOP reduction or treatment success was found. PXF does not appear to be a risk factor for post-laser complications or transient IOP elevation. ${ }^{41,46-48}$

\section{Pigmentary glaucoma}

A diagnosis of pigmentary glaucoma or the degree of TM pigmentation does not appear to affect the success rate of SLT; $;, 47,50$ however, patients with a deeply pigmented TM may be at higher risk of post-SLT complications such as, importantly, sustained IOP elevations. A series of four cases of post-SLT IOP spikes in patients with heavily pigmented angles has been reported, three of whom had pigment dispersion syndrome. The duration of post-SLT IOP elevation was 4 days to 3 months, and three of the four patients went on to require trabeculectomy. The patients were relatively young, taking two to three glaucoma medications prior to SLT, and one had a history of ocular trauma. Laser settings were $30-52$ spots at $0.6-1.0 \mathrm{~mJ}$ laser energy. The authors theorized that it may be necessary to reduce the energy level or number of shots for heavily pigmented angles. ${ }^{51} \mathrm{~A}$ prospective study found a significantly higher rate of mild pain and inflammation and a post-SLT IOP spike of $>6 \mathrm{mmHg}$, as well as a higher need for surgical intervention in patients with pigmentary glaucoma, compared with POAG and PXF. ${ }^{47}$ TM pigmentation was associated with pressure rises after ALT as well. ${ }^{52}$

\section{Steroid-induced glaucoma}

A small study including ten eyes with steroid-induced OHT showed SLT to be effective at lowering IOP in these patients, with a 12 -month mean IOP reduction of $35.9 \%$, which was not significantly different to the IOP reduction for other glaucoma subgroups in this study. ${ }^{53}$ Another small, prospective case control study of 31 eyes showed that prophylactic SLT in patients with a baseline IOP $\geq 21 \mathrm{mmHg}$ prevented IOP elevation after intravitreal triamcinolone injection for diabetic macular edema. ${ }^{54}$

\section{Method of treatment}

Topical anesthetic and a Gonio Laser lens, such as Latina SLT lens (Ocular Instruments, Bellevue, WA, USA), with a 
methylcellulose coupling medium are used. With SLT, the spot size $(400 \mu \mathrm{m})$ and duration (3 ns) are fixed, with the only variable being delivered energy. Compared to the small, $50 \mu \mathrm{m}$ spot diameter in ALT, the SLT spot covers the entire width of the TM making aiming easier. The SLT pilot study ${ }^{20}$ used approximately 50 non-overlapping laser spots placed over $180^{\circ}$ of TM. In this study, the energy level was initially set at $0.8 \mathrm{~mJ}$ and decreased by $0.1 \mathrm{~mJ}$ increments until no visible effects or bubble formation were observed. Typical treatment parameters are 50 (or 100) applications over $180^{\circ}$ (or $360^{\circ}$ ) and laser energy is adjusted to $0.6-1.4 \mathrm{~mJ}$, with an expected endpoint of no visible tissue reaction or small microbubbles. ${ }^{3,6,33,55,56}$ It is assumed that bubble formation is important for the procedure to be effective, but too much bubble formation may lead to a higher rate of inflammation. As transient post-SLT IOP spikes may occur in some patients, apraclonidine $0.5 \%$ (Iopidine; Alcon Laboratories, Inc., Fort Worth, TX, USA) given 1 hour before treatment ${ }^{3,21}$ is common practice. Topical anti-inflammatory drops are not advocated as the induction of an inflammatory response may be involved with the IOP-lowering effect of SLT, and various anti-inflammatory regimes do not correlate with better IOPreduction post-SLT., ${ }^{3,57}$ The symptomatic anterior chamber inflammation occurring in some patients after SLT usually resolves within a few days without treatment. ${ }^{20,35,47,58-60}$

A small, prospective study of 64 patients found no difference between $90^{\circ}$ ( 25 spots) or $180^{\circ}$ (50 spots) SLT in terms of IOP reduction in the treatment success group $(7.01 \mathrm{mmHg}$ versus $6.16 \mathrm{mmHg}$ ) and number of eyes requiring retreatment because of unsatisfactory IOP reduction (47\% versus $41 \%$ eyes) at 7 months. ${ }^{61}$ A more recent RCT of 167 patients randomized to $90^{\circ}, 180^{\circ}$, or $360^{\circ}$ of SLT found that $90^{\circ}$ treatment was significantly less successful than latanoprost and generally ineffective. In the $90^{\circ}$ group, 34\% of eyes achieved $\geq 20 \%$ IOP reduction compared to $65 \%$ in the $180^{\circ}$ and $82 \%$ in the $360^{\circ}$ groups. The $90^{\circ}$ group was discontinued 9 months after randomization because of apparent lack of treatment efficacy. ${ }^{35}$

Two RCTs and one retrospective review ${ }^{23,35,62}$ comparing $180^{\circ}$ with $360^{\circ} \mathrm{SLT}$ found no statistically significant difference in IOP reduction between the two groups.

Novel regimes reported at scientific congresses showed similar efficacy compared with traditional protocols. Laser applied around the limbus on the sclera overlying the TM without a Gonio lens and using the same laser parameters as conventional SLT $\left(100\right.$ shots over $\left.360^{\circ}\right)$ reduced IOP from an average of $20.21 \mathrm{mmHg}$ before treatment to $15.50 \mathrm{mmHg}$ at 6 months $(n=16)$, which was not statistically different from the conventional SLT group (21.14 $\mathrm{mmHg}$ to $15.00 \mathrm{mmHg}$, $\mathrm{n}=16$ ). The direct trans-scleral treatment group experienced a significantly lower rate of complications including superficial punctate keratitis and anterior chamber inflammation. ${ }^{63}$ In a different study, $360^{\circ}$ low-power SLT (0.4 mJ, 50-60 shots) repeated every year for 3-10 years (mean 6.5 years) maintained a higher number of patients on no antiglaucoma medications ( $84 \%$ patients) and a longer mean time to initiation of medical therapy (6.2 years) compared with a conventional $360^{\circ}$ SLT regime (47\% of patients taking no antiglaucoma medications and 3.3 years to initiation of medical therapy). ${ }^{64}$

\section{Predictors of success}

The strongest predictor of success is baseline (pre-SLT) IOP. A RCT showed that higher baseline IOP correlated well with a $\geq 20 \%$ IOP reduction 12 months after SLT (OR $1.58 ; 95 \%$ CI 1.2-2.1). Baseline IOP in the treatment success group ranged from 18 to $36 \mathrm{mmHg}$ and for the nonsuccess group from 16 to $28 \mathrm{mmHg} .{ }^{50}$ A retrospective study using the same definition of treatment success and 6-months follow-up similarly found that SLT efficacy is positively associated with the degree of IOP elevation before SLT treatment. The treatment success group had significantly higher baseline IOP before SLT than the non-success group $(21.75 \pm 4.53 \mathrm{mmHg}$ versus $16.65 \pm 4.32 \mathrm{mmHg})$ with an OR of $1.3(95 \%$ CI $1.16-1.46))^{33}$

Age, sex, race, glaucoma type, previous ALT, myopia, hypertension, diabetes, family history of glaucoma, concurrent antiglaucoma eye drops (including prostaglandin analogs), visual acuity, TM pigmentation, angle grade, lens status (phakic versus pseudophakic), and central corneal thickness were not found to be significant predictors. ${ }^{33,50,65}$

\section{Adverse events}

The reported incidence of mild, transient side effects, presumably related to anterior chamber inflammation, ranges between studies from none to affecting the majority of patients. Although redness, discomfort or pain, and photophobia may occur commonly after SLT, they resolve, without treatment, within a few days. ${ }^{18,33,45,56-58}$

A transient IOP rise of $\geq 5 \mathrm{mmHg}$ occurs in $0 \%-28 \%$ eyes, ${ }^{6,20,25,27,32,35,41,42,46,60,66-68}$ and $\geq 10 \mathrm{mmHg}$ in up to $5.5 \%$ eyes. ${ }^{41,42,67,69}$ It resolves quickly with or without topical antiglaucoma treatment, usually within 24 hours. A systematic review found that empirical, prophylactic treatment reduced the incidence of transient IOP elevation $(28.8 \%$ with treatment compared with $62 \%$ overall incidence). ${ }^{21}$ Following 
ALT, IOP rises of greater than $5 \mathrm{mmHg}$ occurred in $34 \%$ of eyes and IOP rises greater than $10 \mathrm{mmHg}$ in $12 \% .^{52}$

Peripheral anterior synechiae (PAS) occur rarely following SLT, and less often than was observed after ALT. PAS were found in one eye $(1.1 \%-2.85 \%$ of eyes $)$ in two of the nine studies that reported on the presence or absence of PAS after SLT. ${ }^{20,27,29,32,59,66,70-72}$ Forty-six percent of eyes developed PAS after ALT. ${ }^{52}$

There are a few isolated case reports of less common adverse events following SLT, including two occurrences of hyphema, ${ }^{73,74}$ a bilateral anterior uveitis, ${ }^{75}$ and a choroidal effusion. ${ }^{76}$ Four patients with pigmented angles encountered sustained IOP spikes after SLT, as detailed above.

There is one case report of cystoid macular edema after SLT. ${ }^{77}$ However, a prospective study of 64 eyes in which macular thickness was measured by OCT in nine areas (as per the Early Treatment of Diabetic Retinopathy Study protocol), found no significant alteration in retinal thickness at any follow-up visit after SLT and did not prescribe any anti-inflammatory treatment. ${ }^{56}$

A few isolated cases of transient corneal stromal edema, ${ }^{78}$ and one case of diffuse lamellar keratitis in a patient with prior laser in situ keratomileusis ${ }^{79}$ were reported. In practice, transient changes in the corneal endothelium have been noted routinely on slit-lamp examination. This clinical finding has been described as a variable number of white spots in the endothelium which have resolved as early as 24 hours after treatment. The corneal endothelium has been evaluated with specular and confocal microscopy before, immediately after, and 1 month to 6 weeks after SLT. Specular microscopy found dark spots appeared immediately after laser treatment and had resolved by 1 month. ${ }^{80}$ Confocal microscopy revealed areas of hyper-reflectivity corresponding to the location of an individual endothelial cell, and a slight increase in intercellular spacing, 30 minutes after SLT in $88 \%$ of eyes. These changes had resolved before the 6-week follow-up visit. ${ }^{81}$ Both studies showed no significant change in endothelial cell count at 1 month or 6 weeks post-SLT.

\section{Repeatability}

The theoretical advantage of SLT over ALT is that its absence of coagulative damage (fibrosis and scarring) to the TM allows treatment to be repeated. Retrospective studies have looked at the efficacy of repeat SLT after failed primary SLT. ${ }^{82-84}$ Two studies showed that the repeat SLT treatment was at least as effective and may last longer than the initial treatment. In 42 eyes of 42 patients with newly diagnosed POAG,${ }^{82}$ repeat SLT had similar efficacy to primary SLT with respect to IOP reduction ( $\geq 20 \%$ ) and treatment success (reduction of IOP $\geq 20 \%$ and below an individually determined target pressure). The treatment success rate between patients undergoing a second treatment (66\%) was higher but not statistically different to success after primary treatment (55\%). Similarly, mean duration of success after second (13.1 months) and first treatments (6.9 months) was longer but did not reach statistical significance. Survival analysis, however, showed that eyes undergoing repeat SLT had a longer duration of clinical benefit and this was statistically significant. Duration of clinical benefit after SLT was relatively short in this study and repeat treatment was performed at as early as 1 month, which may be related to the treatment regime used (40-50 shots over $360^{\circ}$ compared to 100 shots used more commonly). In 44 eyes of 35 patients with OAG uncontrolled on maximum medical therapy where primary SLT had been successful for at least 6 months, ${ }^{83}$ repeat SLT achieved $\geq 20 \%$ IOP reduction in $43.2 \%$ of eyes at $5-8$ months, which was not as marked as success rate at first treatment (50\%) although the difference was not statistically significant. The interval between first and second treatment did not affect success rate. ${ }^{83}$

One study showed that not all eyes responding to primary SLT responded to repeat SLT. Fifty-one eyes of 34 patients that responded to primary SLT received repeat SLT between 7 and 72 months after their initial treatment. Forty-three percent of eyes achieved $\mathrm{a} \geq 20 \%$ reduction in the average of all IOP readings in the following 12 months. Forty-one percent of eyes that responded to primary SLT achieved the same degree of IOP reduction after repeat SLT ${ }^{84}$ The posttreatment complication rate for repeat SLT was comparable to that reported in other studies for primary SLT.

\section{Cost}

Economic modeling shows that if SLT and topical medications have similar efficacy, SLT alone as primary, rather than second-line, treatment for POAG is cost-saving, and the associated savings increase over time in an aging population as more people are diagnosed and treated. ${ }^{85}$

The projected cost over a 6 -year period to a health service provider (Ontario Health Insurance Plan) predicted a modest cost saving with SLT over medical therapy as primary treatment for OAG. The cost of performing $180^{\circ}$ bilateral SLT was 370 Canadian Dollars (CAD), taken from the Schedule of Benefits for Physician Services. Average annual costs for generic versions of six medication classes (prostaglandins, beta-blockers, carbonic anhydrase inhibitors, alpha-agonists, combination drugs, and pilocarpine) were calculated with 
reference to a retrospective study of prescription refill frequency of 27,000 patients, in order to account for misadministration and noncompliance. Charts of 707 glaucoma patients were randomly selected to determine a representative utilization rate of glaucoma medications. The annual cost per medication ranged from 17.66 CAD for pilocarpine to 305.74 CAD for a dorzolamide-timolol combination, with the most commonly prescribed group, prostaglandin analogs, costing 271.81 CAD per annum. Forty-two percent of patients were taking two or three medications, making the yearly mean cost for all glaucoma medications 344 CAD per patient. The 6-year cumulative cost saving between SLT and medical treatment assumed that SLT was repeatable every 2 or 3 years. Using the scenario that SLT would be repeated after 2 years, SLT produced a 6-year saving over mono-, bi-, and tri-drug therapy of 206.54, 1,668.64, and 2,992.67 CAD per patient, respectively. If duration between SLT treatments were 3 years, the savings would be 580.52 , 2,042.82, and 3,366.65 CAD, respectively. This study used the theoretical scenario in which every patient will respond to SLT, and patients who fail SLT and require adjunctive medication were not included. Using the results of studies examining duration of SLT success, the outcomes would be valid for up to $85 \%$ of patients treated every 2 years and $74 \%$ of patients treated every 3 years, assuming the repeatability of SLT shown in retrospective studies. ${ }^{82,83}$ Costs associated with drop toxicity and allergy were also not included and their incorporation could potentially increase the cost of medical treatment.

\section{Conclusion}

SLT is as effective as medications and ALT at lowering IOP in OHT, primary open-angle, PXF, pigmentary, and steroidinduced glaucoma. It is successful as both initial and adjunctive treatment in these patients. SLT does not rely on patients' compliance with eye drops, which is traditionally low, and side effects associated with drop toxicity are also avoided. Common adverse effects - namely discomfort and redness - are mild and transient. Sustained IOP spikes are rare and associated with heavily pigmented angles. Lower energy settings are recommended for pigmented angles as SLT selectively targets pigment in the TM. SLT is not uniformly effective in all eyes, and its IOP-lowering effect decreases over time. High pretreatment IOP is the strongest predictor of SLT success; however, significant IOP reduction has also been shown in patients with NTG and patients already taking multiple antiglaucoma drops. Available evidence suggests that repeat SLT achieves a good pressure reduction after successive treatments, and this makes SLT a cost-effective glaucoma treatment.

\section{Disclosure}

The authors report no conflicts of interest in this work.

\section{References}

1. Latina MA, Park C. Selective targeting of trabecular meshwork cells: in vitro studies of pulsed and CW laser interactions. Exp Eye Res. 1995; 60(4):359-371.

2. Damji KF. II. Selective Laser Trabeculoplasty: A Better Alternative. Surv Ophthalmol. 2008;53(6):646-651.

3. Latina MA, de Leon JM. Selective laser trabeculoplasty. Ophthalmol Clin North Am. 2005;18(3):409-419.

4. No authors listed. The Glaucoma Laser Trial (GLT) 2. Results of argon laser trabeculoplasty versus topical medicines. The Glaucoma Laser Trial Research Group. Ophthalmology. 1990;97(11): $1403-1413$.

5. Krasnov MM. Q-switched laser goniopuncture. Arch Ophthalmol. 1974;92(1):37-41.

6. Melamed S, Ben Simon GJ, Levkovitch-Verbin H. Selective laser trabeculoplasty as primary treatment for open-angle glaucoma: a prospective, nonrandomized pilot study. Arch Ophthalmol. 2003;121(7): 957-960.

7. Stein JD, Challa P. Mechanisms of action and efficacy of argon laser trabeculoplasty and selective laser trabeculoplasty. Curr Opin Ophthalmol. 2007;18(2):140-145.

8. Kramer TR, Noecker RJ. Comparison of the morphologic changes after selective laser trabeculoplasty and argon laser trabeculoplasty in human eye bank eyes. Ophthalmology. 2001;108(4):773-779.

9. Cvenkel B, Hvala A, Drnovsek-Olup B, Gale N. Acute ultrastructural changes of the trabecular meshwork after selective laser trabeculoplasty and low power argon laser trabeculoplasty. Lasers Surg Med. 2003;33(3):204-208.

10. Damji KF, Shah KC, Rock WJ, Bains HS, Hodge WG. Selective laser trabeculoplasty $\mathrm{v}$ argon laser trabeculoplasty: a prospective randomised clinical trial. Br J Ophthalmol. 1999;83(6):718-722.

11. Dueker DK, Norberg M, Johnson DH, Tschumper RC, Feeney-Burns L. Stimulation of cell division by argon and Nd:YAG laser trabeculoplasty in cynomolgus monkeys. Invest Ophthalmol Vis Sci. 1990;31(1):115-124.

12. Guzey M, Vural H, Satici A, Karadede S, Dogan Z. Increase of free oxygen radicals in aqueous humour induced by selective Nd:YAG laser trabeculoplasty in the rabbit. Eur J Ophthalmol. 2001;11(1): $47-52$.

13. Alvarado JA, Iguchi R, Martinez J, Trivedi S, Shifera AS. Similar effects of selective laser trabeculoplasty and prostaglandin analogs on the permeability of cultured Schlemm canal cells. Am J Ophthalmol. 2010;150(2):254-264.

14. Leahy K, Sarris M, Di Girolamo N, Watson SL, et al. Investigation of corneal endothelial changes post selective laser trabeculoplasty. Invest Ophthalmol Vis Sci. 2014;55(13):6162.

15. Bradley JM, Anderssohn AM, Colvis CM, et al. Mediation of laser trabeculoplasty-induced matrix metalloproteinase expression by IL-1beta and TNFalpha. Invest Ophthalmol Vis Sci. 2000;41(2):422-430.

16. Alvarado JA, Katz LJ, Trivedi S, Shifera AS. Monocyte modulation of aqueous outflow and recruitment to the trabecular meshwork following selective laser trabeculoplasty. Arch Ophthalmol. 2010; 128(6):731-737.

17. Bylsma SS, Samples JR, Acott TS, Van Buskirk EM. Trabecular cell division after argon laser trabeculoplasty. Arch Ophthalmol. 1988; 106(4):544-547.

18. Acott TS, Samples JR, Bradley JMB, Bacon DR, Bylsma SS, Van Buskirk EM. Trabecular repopulation by anterior trabecular meshwork cells after laser trabeculoplasty. Am J Ophthalmol. 1989;107(1):1-6.

19. Brinkmann R, Hüttmann G, Rögener J, Roider J, Birngruber R, Lin CP. Origin of retinal pigment epithelium cell damage by pulsed laser irradiance in the nanosecond to microsecond time regimen. Lasers Surg Med. 2000;27:451-464. 
20. Latina MA, Sibayan SA, Shin DH, Noecker RJ, Marcellino G. Q-switched 532-nm Nd:YAG laser trabeculoplasty (selective laser trabeculoplasty): a multicenter, pilot, clinical study. Ophthalmology. 1998;105(11):2082-2088; discussion 2089-2090.

21. Wong MO, Lee JW, Choy BN, Chan JC, Lai JS. Systematic review and meta-analysis on the efficacy of selective laser trabeculoplasty in open-angle glaucoma. Surv Ophthalmol. 2015;60(1):36-50.

22. Martinez-de-la-Casa JM, Garcia-Feijoo J, Castillo A, et al. Selective vs argon laser trabeculoplasty: hypotensive efficacy, anterior chamber inflammation, and postoperative pain. Eye (Lond). 2004; 18(5):498-502.

23. Woo DM, Healey PR, Graham SL, Goldberg I. Intraocular pressurelowering medications and long-term outcomes of selective laser trabeculoplasty. Clin Experiment Ophthalmol. Epub 2014 Oct 7.

24. Gracner T, Falez M, Gracner B, Pahor D. [Long-term follow-up of selective laser trabeculoplasty in primary open-angle glaucoma]. Klin Monbl Augenheilkd. 2006;223(9):743-747. German.

25. Kent SS, Hutnik CM, Birt CM, et al. A Randomized Clinical Trial of Selective Laser Trabeculoplasty Versus Argon Laser Trabeculoplasty in Patients With Pseudoexfoliation. J Glaucoma. Epub 2013 Jul 17.

26. Birt CM. Selective laser trabeculoplasty retreatment after prior argon laser trabeculoplasty: 1-year results. Can J Ophthalmol. 2007; 42(5):715-719.

27. Katz LJ, Steinmann WC, Kabir A, et al. Selective laser trabeculoplasty versus medical therapy as initial treatment of glaucoma: a prospective, randomized trial. J Glaucoma. 2012;21(7):460-468.

28. Weinand FS, Althen F. Long-term clinical results of selective laser trabeculoplasty in the treatment of primary open angle glaucoma. Eur J Ophthalmol. 2006;16(1):100-104.

29. McIlraith I, Strasfeld M, Colev G, Hutnik CM. Selective laser trabeculoplasty as initial and adjunctive treatment for open-angle glaucoma. J Glaucoma. 2006;15(2):124-130.

30. Rosenfeld E, Shemesh G, Kurtz S. The efficacy of selective laser trabeculoplasty versus argon laser trabeculoplasty in pseudophakic glaucoma patients. Clin Ophthalmol. 2012;6:1935-1940.

31. Liu Y, Birt CM. Argon versus selective laser trabeculoplasty in younger patients: 2-year results. J Glaucoma. 2012;21(2):112-115.

32. Lai JS, Chua JK, Tham CC, Lam DS. Five-year follow up of selective laser trabeculoplasty in Chinese eyes. Clin Experiment Ophthalmol. 2004;32(4):368-372.

33. Martow E, Hutnik CM, Mao A. SLT and adjunctive medical therapy: a prediction rule analysis. J Glaucoma. 2011;20(4):266-270.

34. Nagar M, Luhishi E, Shah N. Intraocular pressure control and fluctuation: the effect of treatment with selective laser trabeculoplasty. Br J Ophthalmol. 2009;93(4):497-501.

35. Nagar M, Ogunyomade A, O'Brart DP, Howes F, Marshall J. A randomised, prospective study comparing selective laser trabeculoplasty with latanoprost for the control of intraocular pressure in ocular hypertension and open angle glaucoma. Br J Ophthalmol. 2005; 89(11):1413-1417.

36. Juzych MS, Chopra V, Banitt MR, et al. Comparison of long-term outcomes of selective laser trabeculoplasty versus argon laser trabeculoplasty in open-angle glaucoma. Ophthalmology. 2004; 111(10): 1853-1859.

37. Bovell AM, Damji KF, Hodge WG, Rock WJ, Buhrmann RR, Pan YI. Long term effects on the lowering of intraocular pressure: selective laser or argon laser trabeculoplasty? Can J Ophthalmol. 2011; 46(5):408-413.

38. Schwartz GF, Quigley HA. Adherence and persistence with glaucoma therapy. Surv Ophthalmol. 2008;53 Suppl 1:S57-S68.

39. McAlinden C. Selective laser trabeculoplasty (SLT) vs other treatment modalities for glaucoma: systematic review. Eye (Lond). 2014;28(3):249-258.

40. Waisbourd M, Katz LJ. Selective laser trabeculoplasty as a first-line therapy: a review. Can J Ophthalmol. 2014;49(6):519-522.
41. Shazly TA, Smith J, Latina MA. Long-term safety and efficacy of selective laser trabeculoplasty as primary therapy for the treatment of pseudoexfoliation glaucoma compared with primary open-angle glaucoma. Clin Ophthalmol. 2010;5:5-10.

42. Francis BA, Ianchulev T, Schofield JK, Minckler DS. Selective laser trabeculoplasty as a replacement for medical therapy in open-angle glaucoma. Am J Ophthalmol. 2005;140(3):524-525.

43. Prasad N, Murthy S, Dagianis JJ, Latina MA. A comparison of the intervisit intraocular pressure fluctuation after 180 and 360 degrees of selective laser trabeculoplasty (SLT) as a primary therapy in primary open angle glaucoma and ocular hypertension. $J$ Glaucoma. 2009;18(2):157-160

44. Tojo N, Oka M, Miyakoshi A, Ozaki H, Hayashi A. Comparison of fluctuations of intraocular pressure before and after selective laser trabeculoplasty in normal-tension glaucoma patients. J Glaucoma. 2014;23(8):e138-e143.

45. Gracner T. Intraocular pressure response of capsular glaucoma and primary open-angle glaucoma to selective Nd: YAG laser trabeculoplasty: a prospective, comparative clinical trial. Eur J Ophthalmol. 2002; 12(4):287-292.

46. Goldenfeld M, Geyer O, Segev E, Kaplan-Messas A, Melamed S. Selective laser trabeculoplasty in uncontrolled pseudoexfoliation glaucoma. Ophthalmic Surg Lasers Imaging. 2011;42(5):390-393.

47. Koucheki B, Hashemi H. Selective laser trabeculoplasty in the treatment of open-angle glaucoma. J Glaucoma. 2012;21(1):65-70.

48. Ayala M, Chen E. Comparison of selective laser trabeculoplasty (SLT) in primary open angle glaucoma and pseudoexfoliation glaucoma. Clin Ophthalmol. 2011;5:1469-1473.

49. Gracner T, Gracner B, Pahor D. Comparative study of the efficacy of selective laser trabeculoplasty for pseudoexfoliation glaucoma and primary open-angle glaucoma. Zdrav Vestn. 2004;73:439-443.

50. Hodge WG, Damji KF, Rock W, Buhrmann R, Bovell AM, Pan Y. Baseline IOP predicts selective laser trabeculoplasty success at 1 year posttreatment: results from a randomised clinical trial. Br J Ophthalmol. 2005;89(9):1157-1160.

51. Harasymowycz PJ, Papamatheakis DG, Latina M, De Leon M, Lesk MR, Damji KF. Selective laser trabeculoplasty (SLT) complicated by intraocular pressure elevation in eyes with heavily pigmented trabecular meshworks. Am J Ophthalmol. 2005;139(6):1110-1113.

52. The Glaucoma Laser Trial. I. Acute effects of argon laser trabeculoplasty on intraocular pressure. Glaucoma Laser Trial Research Group. Arch Ophthalmol. 1989;107(8):1135-1142.

53. Tokuda N, Inoue J, Yamazaki I, et al. [Effects of selective laser trabeculoplasty treatment in steroid-induced glaucoma]. Nippon Ganka Gakkai Zasshi. 2012;116(8):751-757. Japanese.

54. Bozkurt E, Kara N, Yazici AT, et al. Prophylactic selective laser trabeculoplasty in the prevention of intraocular pressure elevation after intravitreal triamcinolone acetonide injection. Am J Ophthalmol. 2011;152(6):976-981.e972.

55. Samples JR, Singh K, Lin SC, et al. Laser trabeculoplasty for openangle glaucoma: a report by the American Academy of Ophthalmology. Ophthalmology. 2011;118(11):2296-2302.

56. Klamann MK, Maier AK, Gonnermann J, Ruokonen PC. Adverse effects and short-term results after selective laser trabeculoplasty. J Glaucoma. 2014;23(2):105-108.

57. Realini T, Charlton J, Hettlinger M. The impact of anti-inflammatory therapy on intraocular pressure reduction following selective laser trabeculoplasty. Ophthalmic Surg Lasers Imaging. 2009;41(1):100-103.

58. Mahdy MA. Efficacy and safety of selective laser trabeculoplasty as a primary procedure for controlling intraocular pressure in primary open angle glaucoma and ocular hypertensive patients. Sultan Qaboos Univ Med J. 2008;8(1):53-58.

59. Nitta K, Sugiyama K, Mawatari Y, Tanahashi T. [Results of selective laser trabeculoplasty (SLT) as initial treatment for normal tension glaucoma]. Nippon Ganka Gakkai Zasshi. 2013;117(4):335-343. Japanese. 
60. Realini T. Selective laser trabeculoplasty for the management of open-angle glaucoma in St Lucia. JAMA Ophthalmol. 2013;131(3): 321-327.

61. Chen E, Golchin S, Blomdahl S. A comparison between 90 degrees and 180 degrees selective laser trabeculoplasty. J Glaucoma. 2004; 13(1):62-65.

62. Goyal S, Beltran-Agullo L, Rashid S, et al. Effect of primary selective laser trabeculoplasty on tonographic outflow facility: a randomised clinical trial. Br J Ophthalmol. 2010;94(11):1443-1447.

63. Belkin M, et al. Invest Ophthalmol Vis Sci. 2014;55:ARVO E-Abstract 819.

64. Gandolfi S, et al. Invest Ophthalmol Vis Sci. 2014;55:ARVO E-Abstract 818

65. Tzimis V, Tze L, Ganesh J, et al. Laser trabeculoplasty: an investigation into factors that might influence outcomes. Can J Ophthalmol. 2011;46(4):305-309.

66. Abdelrahman AM, Eltanamly RM. Selective laser trabeculoplasty in Egyptian patients with primary open-angle glaucoma. Middle East Afr J Ophthalmol. 2012;19(3):299-303.

67. Almeida ED Jr, Pinto LM, Fernandes RA, Prata TS. Pattern of intraocular pressure reduction following laser trabeculoplasty in open-angle glaucoma patients: comparison between selective and nonselective treatment. Clin Ophthalmol. 2011;5:933-936.

68. Shibata M, Sugiyama T, Ishida O, et al. Clinical results of selective laser trabeculoplasty in open-angle glaucoma in Japanese eyes: comparison of 180 degree with 360 degree SLT. J Glaucoma. 2012;21(1): 17-21.

69. Song J, Lee PP, Epstein DL, et al. High failure rate associated with 180 degrees selective laser trabeculoplasty. J Glaucoma. 2005; 14(5):400-408.

70. Babighian S, Caretti L, Tavolato M, Cian R, Galan A. Excimer laser trabeculotomy vs 180 degrees selective laser trabeculoplasty in primary open-angle glaucoma. A 2-year randomized, controlled trial. Eye (Lond). 2010;24(4):632-638.

71. Tang M, Fu Y, Fu M, et al. The efficacy of low-energy selective laser trabeculoplasty. Ophthalmic Surg Lasers Imaging. 2011;42(1): 59-63.

72. Damji KF, Bovell AM, Hodge WG, et al. Selective laser trabeculoplasty versus argon laser trabeculoplasty: results from a 1-year randomised clinical trial. Br J Ophthalmol. 2006;90(12):1490-1494.
73. Shihadeh WA, Ritch R, Liebmann JM. Hyphema occurring during selective laser trabeculoplasty. Ophthalmic Surg Lasers Imaging. 2006;37(5):432-433.

74. Rhee DJ, Krad O, Pasquale LR. Hyphema following selective laser trabeculoplasty. Ophthalmic Surg Lasers Imaging. 2009;40(5):493-494.

75. Koktekir BE, Gedik S, Bakbak B. Bilateral severe anterior uveitis after unilateral selective laser trabeculoplasty. Clin Experiment Ophthalmol. 2013;41(3):305-307.

76. Kim DY, Singh A. Severe iritis and choroidal effusion following selective laser trabeculoplasty. Ophthalmic Surg Lasers Imaging. 2008;39(5):409-411.

77. Wechsler DZ, Wechsler IB. Cystoid macular oedema after selective laser trabeculoplasty. Eye (Lond). 2010;24(6):1113.

78. Moubayed SP, Hamid M, Choremis J, Li G. An unusual finding of corneal edema complicating selective laser trabeculoplasty. Can J Ophthalmol. 2009;44(3):337-338.

79. Holz H, Pirouzian A. Bilateral diffuse lamellar keratitis following consecutive selective laser trabeculoplasty in LASIK patient. J Cataract Refract Surg. 2010;36(5):847-849.

80. Ong K, Ong L, Ong L. Corneal endothelial changes after selective laser trabeculoplasty. Clin Experiment Ophthalmol. 2013;41(6): 537-540.

81. White AJ, Mukherjee A, Hanspal I, Sarkies NJ, Martin KR, Shah P. Acute transient corneal endothelial changes following selective laser trabeculoplasty. Clin Experiment Ophthalmol. 2013;41(5): 435-441.

82. Avery N, Ang GS, Nicholas S, Wells A. Repeatability of primary selective laser trabeculoplasty in patients with primary open-angle glaucoma. Int Ophthalmol. 2013;33(5):501-506.

83. Hong BK, Winer JC, Martone JF, Wand M, Altman B, Shields B. Repeat selective laser trabeculoplasty. J Glaucoma. 2009;18(3):180-183.

84. Khouri AS, Lin J, Berezina TL, Maltzman B, Fechtner RD. Repeat selective laser trabeculoplasty can be effective in eyes with initial modest response. Middle East Afr J Ophthalmol. 2014;21(3):205-209.

85. Dirani M, Crowston JG, Taylor PS, et al. Economic impact of primary open-angle glaucoma in Australia. Clin Experiment Ophthalmol. 2011;39(7):623-632.
Clinical Ophthalmology

\section{Publish your work in this journal}

Clinical Ophthalmology is an international, peer-reviewed journal covering all subspecialties within ophthalmology. Key topics include: Optometry; Visual science; Pharmacology and drug therapy in eye diseases; Basic Sciences; Primary and Secondary eye care; Patient Safety and Quality of Care Improvements. This journal is indexed on Submit your manuscript here: http://www.dovepress.com/clinical-ophthalmology-journal

\section{Dovepress}

PubMed Central and CAS, and is the official journal of The Society of Clinical Ophthalmology (SCO). The manuscript management system is completely online and includes a very quick and fair peer-review system, which is all easy to use. Visit http://www.dovepress.com/ testimonials.php to read real quotes from published authors. 